\title{
Developing Fabrication Technologies to Provide On Demand Manufacturing for Exploration of the Moon and Mars
}

\author{
Monica S. Hammond ${ }^{*}$ \\ NASA/Marshall Space Flight Center, Huntsville, AL 35812 \\ James E. Good ${ }^{\dagger}$ \\ MEI Technologies, Inc., Huntsville, AL 35805 \\ Scott D. Gilley ${ }^{\ddagger}$ \\ Tec-Masters, Inc., Huntsville, AL 35872 \\ and \\ Richard W. Howard ${ }^{\S}$ \\ Teledyne Brown Engineering, Huntsville, AL 35805
}

\begin{abstract}
NASA's human exploration initiative poses great opportunity and risk for manned and robotic missions to the Moon, Mars, and beyond. Engineers and scientists at the Marshall Space Flight Center (MSFC) are developing technologies for in situ fabrication capabilities during lunar and Martian surface operations utilizing provisioned and locally refined materials. Current fabrication technologies must be advanced to support the special demands and applications of the space exploration initiative such as power, weight and volume constraints. In Situ Fabrication and Repair (ISFR) will advance state-of-the-art technologies in support of habitat structure development, tools, and mechanical part fabrication. The repair and replacement of space mission components, such as life support items or crew exercise equipment, fall within the ISFR scope. This paper will address current fabrication technologies relative to meeting ISFR targeted capabilities, near-term advancement goals, and systematic evaluation of various fabrication methods.
\end{abstract}

\section{Introduction}

The ISFR Element was defined by the Office of Biological and Physical Research (OBPR) in response to the Human Support Systems (HSS) Program. The ISFR Element is managed as a technology and hardware development program at the MSFC in Huntsville, Alabama. The ISFR Element has the charter to provide fabrication and repair of equipment and materials on location during space missions. The scope of this activity includes all mechanical and electronic components and assemblies to progress, in a phased approach, and meet the increasing scope of the Exploration Initiative. This includes the development of supporting fabrication, repair, and habitat structure technologies for manned missions, which maximize the use of in situ resources and address the following agency topics:

\footnotetext{
* Fabrication Technologies Project Manager, Technology \& Capability Development Projects Office/SY10

${ }^{\dagger}$ ISFR-Fabrication Technologies Element Systems Engineer, Teledyne Brown Engineering/MS60

‡ ISFR-Fabrication Technologies Element Lead Systems Engineer, Teledyne Brown Engineering/MS60

${ }^{\S}$ ISFR-Fabrication Technologies Element Systems Engineer, Teledyne Brown Engineering/MS60
} 
1. Bioastronautics Roadmap (BR) (Ref. 1) risks

2. Strategic Technical Challenges defined in the Human \& Robotics Technology (H\&RT) Formulation Plan (Ref. 2).

The ISFR Element supports the entire life cycle of the HSS program, enabling the evolution of human space exploration by reducing downtime of failed components, decreasing risk to crew, improving system functionality, and enhancing mission safety. ISFR capabilities will help reduce crew exposure to harsh space environments by providing autonomous, non-destructive evaluation technologies capable of identifying and confirming a failure or validating that a repair was successful. ISFR provides habitat manufacturing and assembly technologies that incorporate in situ resources to produce autonomous, affordable, pre-positioned habitat environments. These habitats feature radiation shielding and protection from micrometeoroids and exhaust plumes. The Element strives to reduce upmass and upvolume resource requirements for supply of spares and materials from Earth by utilizing in situ resources. A major goal will be to provide just-in-time fabrication of parts and tools to address system failures via closed loop, quality controlled, solid, freeform fabrication technologies. Such a system would reduce spare parts inventory. In addition, ISFR is investigating just-in-time repair capability using soldering, patching, and adhesives.

The ISFR Element is composed of the following sub-elements:

1. Fabrication Technologies sub-element: Includes parts and tools fabricated using additive, subtractive, conventional, and hybrid technologies, using metals, ceramics, and composites.

2. Repair and Non-Destructive Evaluation (NDE) Technologies sub-element: Includes mobile, shop, portable, and hand-held equipment to develop repair and inspection capabilities.

3. Habitat Structures sub-element: Structural and radiation shielding fabrication and repair capabilities.

During the summer of 2005, the ISFR Element conducted an independent Technical Interchange Meeting (TIM) for each sub-element. The objective of this activity was to conduct a documented, in-depth review of the ISFR technologies being presented, using a customer and peer review panel format. These review groups consisted of qualified individuals who were independent of the ISFR teams performing the work. The TIMs provided an excellent opportunity for an exchange of ideas between the fields of expertise, opened new lines of communication, and expanded areas of understanding. At the conclusion of each TIM, the panel members held discussions (within their respective groups) to assess how well the addressed sub-element, programmatic issues related to the chosen technologies. Topics of discussions include but are not limited to the following issues: Do the technologies fulfill the needs to successfully establish a long duration presence on the moon? Have the sub-elements discovered all of the technical issues related to the chosen technologies, and is it possible to overcome any technology gaps? Does the development plan follow a logical flow? This paper focuses on a summary of the Fabrication Technologies subelement activities, which are specifically responsible for the development of fabrication methods in support of the ISFR capability goals.

\section{Fabrication Technologies Sub-Element Overview}

The Fabrication Technologies sub-element provides a means of building new or replacing existing parts or tools during space missions. This includes the capability to build newly defined parts or tools within an element of the space transport vehicle, other vehicle equipment, or habitat equipment. The sub-element will use available materials as provided by a logistics support function, which may include new and/or recycled materials composed of ceramics or metals. New materials will be inclusive of materials delivered from Earth or obtained and processed in situ. Parts will initially include various metal material types to fulfill requirements for all functioning elements used in the in situ equipment and habitat.

Prior to the TIM, the Fabrication team had issued a detailed trade study relative to additive, subtractive, and hybrid manufacturing technologies, which selected possible candidates for continued evaluation as spaceflight fabrication systems. The primary criteria were the variety of material types that the systems could process.

The trade study activity served to identify core technologies that will close gaps in current manufacturing technologies for space missions. They were identified by engineering judgment of factors such as fabrication speed 
limitations, geometric accuracy, and tolerance assessment (see Figure 1); material properties (see Figure 2); and resource savings that may be realized by the enhancement of current state-of-the-art processing methods.

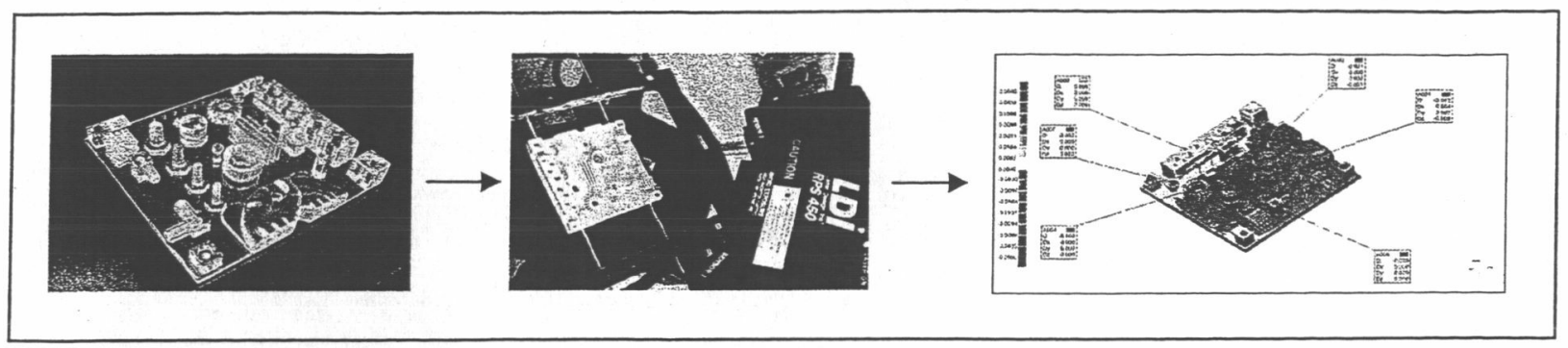

Figure 1. Laser Scanning of Benchmark Part and Resulting Analysis Report

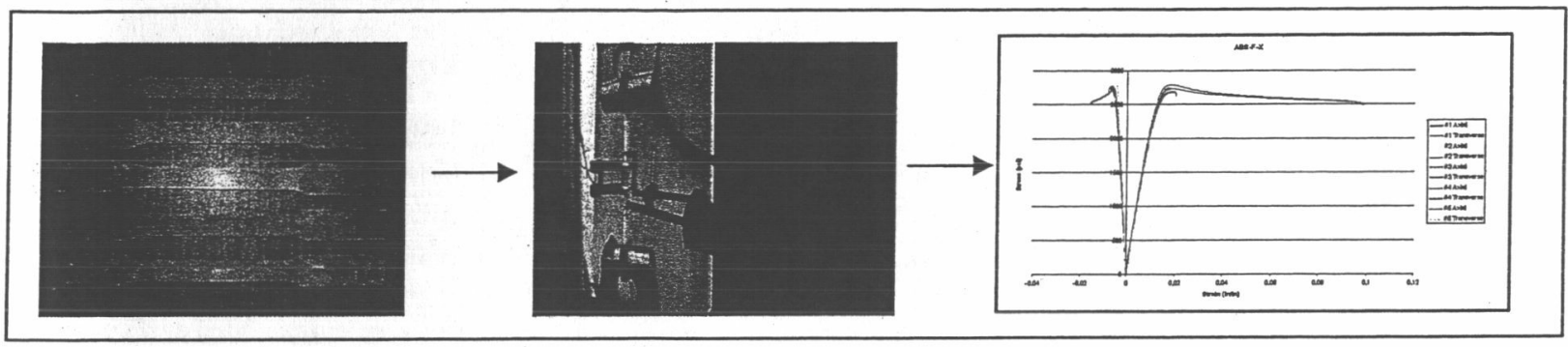

Figure 2. Tensile Testing of Manufactured Specimen and Resulting Analysis Report

The type of feedstock that these technologies utilize was an important criterion in the evaluation process. Management and usage of bulk powders, sprayed powders, wires, filaments, tapes, stock shapes (i.e., plate, channels, ells, tees, etc.), and liquids, were evaluated for microgravity and hypo-gravity applications. In addition, the possibility of producing these feedstocks from in situ regolith or a recycle stream was also evaluated.

Most of these existing manufacturing technologies (i.e., ground based equipment) are heavy and large and require relatively large amounts of alternating current power. Development of units for spaceflight must be designed for weight and volume reduction and utilization of alternative power sources. The spaceflight systems must be ruggedized to survive launch and landing loads, while providing long Mean Time Between Failures (MTBF).

\section{A. Fabrication Technology Development Activities}

The Fabrication Technologies team received several helpful suggestions from the TIM Review Panels; however, the two primary recommendations were to:

1. "Infiltrate" Fabrication Technologies into the front-end space mission systems design activities

2. Reduce initial scope to focus on highest priority materials (i.e., metals and ceramics).

Infiltrating Fabrication Technologies into the front-end mission systems design activities has both short-term and long-term ramifications. Currently, developing technologies exist that can provide capabilities that state-of-the-art processes cannot satisfy. While the ultimate goal is to establish fabrication techniques applicable to lunar or Martian onsite operations, successes to ground-based systems will provide credibility and opportunities for technology development. Prior to the TIM, the Fabrication Technologies team was already collaborating with the Propulsion Systems Combustion Design and Development Department at MSFC in an effort to fabricate a subset of complex combustion parts (i.e., interface plates, nozzles, manifolds, thrust chamber liners, etc.). The Combustion Design team provided the Computer Aided Design (CAD) files, which were imported into the existing manufacturing system software. Using Solid Free Form (SFF) Rapid Prototyping techniques, the production time for the development of these parts was greatly reduced. Once fabricated, these development articles were turned over to the Combustion Design team in order to be integrated into the hardware test complement proposed for an engine burn 
on Test Stand 115 at MSFC. These efforts may result in an improved product to the propulsion group, while the technology has an opportunity to mature and improvements may be made to the process.

As a separate design collaboration activity, the Fabrication Technologies team worked with the Environmental Control and Life Support System (ECLSS) team to develop parts for the Water Processing Assembly (WPA), the Air Revitalization Subsystem, and the Urine Processor Distillation Assembly. The Fabrication team saw an opportunity to improve the existing systems. These assemblies use packed beds of pellets for filtration and as an adsorbent system. These systems tend to create debris caused by the friction of the pellets rubbing against each other during thermal cycles. This results in clogged valves and also results in inefficiencies in the flow through the packed beds. This has been an ongoing problem for these assemblies. Using additive techniques, a lattice structure can be manufactured and can function in a manner similar to a packed bed without the creation of debris. Optimally, the lattice structure would result in a decrease in pressure drop through the adsorbent bed and would also eliminate the debris. This would eliminate the clogged valves and improve efficiency. Preliminary results show a significant improvement in the pressure drop of the system, resulting in a decrease of power required to run the assemblies. A more detailed description of these lattice structures is provided below.

Using rapid prototyping techniques, the Fabrication Team developed a ceramic alumina lattice structure for later impregnation with a catalyst. The monolithic lattice structures were fabricated using layered manufacturing technologies and have been flow tested using the ECLSS bench-top test system. Initial results indicated that a very favorable reduction in pressure drop appears attainable in comparison to the existing packed pellet beds. Testing of additional lattice designs will be continued with a complement of 4 units for optimization of the flow characteristics of the lattice weave and pore openings. If future testing is successful for adsorbent performance, this structure may replace the existing ECLSS catalyst bed of pelletized clay and zeolite. See Figure 3 for a photograph of the ceramic lattice structure and Figure 4 for a compound

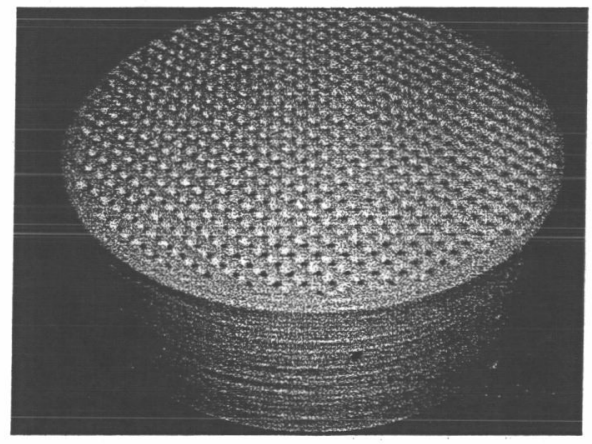

Figure 3. Ceramic (Alumina) Lattice Structure pulley and driver gear.

The long-term benefits of participating in the early design phases for Exploration efforts include the demonstration of possible weight savings, parts count reduction, and unique geometries made possible by layered manufacturing processes. The ability to produce unique geometries can be capitalized upon through weight saving honeycomb structures and also through parts with internal cavities, such as flow passages, functional gradient materials, and ordered lattices. Also important is the determination of process limitations, such as restricted part size, material properties variations, and attainable surface finish. With this information, process improvements can be made that will reduce technology gaps which might preclude fabrication in space in the long term and improve existing systems in the short term.

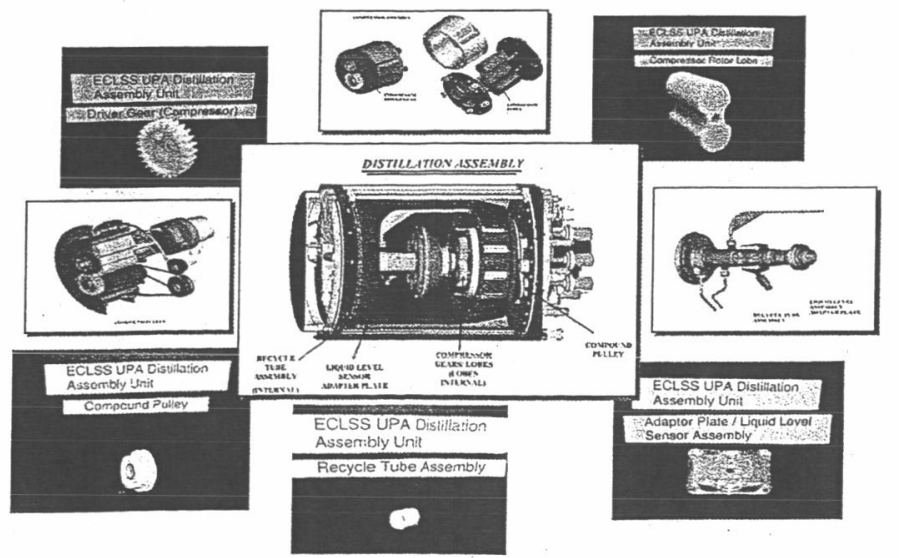

Figure 4. ISS ECLSS Urine Processor Distillation Assembly Parts 


\section{B. Fabrication Technology Selection Activities}

An initial study of current fabrication technologies shows that there is no single solution for fabrication systems in space. The anticipated approach will instead involve a combination of technologies to provide critical capabilities. Additive manufacturing techniques offer potential reduction of feedstock requirements since parts are built to size rather than subtractively machined down from larger bulk stock. However, utilizing Computer Numerically Controlled (CNC) machining as a post-processing function will allow additive manufacturing techniques to provide improved dimensional accuracy and surface finish. With industry demanding better surface finishes and dimensional accuracy, the technology gap is closing between additive techniques and CNC machining. Incorporating $\mathrm{CNC}$ machining processes integral to the overall system or as post-finishing steps is currently envisioned as necessary to provide the needed accuracies. The reduced gravity on the lunar and Martian surfaces will affect fabrication processes that must be considered in the technology selection approach. Partial gravity effects on the Moon and Mars will also need to be addressed for CNC such as debris handling and coolant management aspects. Gravity changes will also have a negative effect on additive processes due to heat and mass transfer differences.

Additive manufacturing techniques are good complements to $\mathrm{CNC}$ machining since some of the advantages include the ability to produce complex geometries as well as the potential to form functional gradient materials. Additive techniques can also successfully produce complex internal cavities where $\mathrm{CNC}$ machining can not. These two techniques functioning in tandem would provide improved capability over either single process.

Additive manufacturing technologies encompass several different techniques that are based on layered part build up. These processes also have unique material sets dependent upon specific manufacturing techniques. When evaluating additive methods, the unique material set must support the Exploration Initiative.

Before evaluating very concise additive techniques, the target material set must be defined. Technical interchange meetings with selected programs at NASA/MSFC were conducted to determine material needs. Some of these programs included:

- Wind Tunnel Test Program

- Propulsion Team (Combustion Devices)

- Crew Exploration Vehicle (CEV)/Crew Launch Vehicle (CLV) Team

- Turbo-Machinery Team (within the Propulsion Team).

Additional existing data was reviewed for pertinent information including the Material Identification and Usage Lists (MIULs) of Space Station and Shuttle Mid-Deck Payloads. Another source of information used to determine the material set was a compilation of failure data representing selected space vehicles. This list contained failed components as well as the component material. The list provided insight into the type of components that may require replacement, as well as the type of components requiring fabrication during a long duration stay on the Moon or Mars.

A determination was made after the TIM to concentrate on the fabrication of metal components in the early development phase. A subsequent trade study was performed to investigate additive techniques that could manufacture metal parts. The systems selected for evaluation included the following technologies, which were assessed for their metal fabrication capabilities:

- Selective Laser Sintering (SLS®)-EOS®

- $\quad$ Laser Engineered Net Shaping (LENS®)

- $\quad$ POM Group - Direct Metal Deposition (DMD®)

- Ultrasonic Consolidation (UC)
- Arcam Electron Beam Melting (EBM)

- Prometal 3DP

- SLS@-3D SYSTEMS

The trade study focused on two specific areas, including the part quality and material set. A $50 \%$ weighting was placed on the quality of the part, including capabilities of the system with respect to the part build volume, geometrical tolerances, and surface finish, among others. Relative rankings were then assigned to each system for all part quality criteria. A 50\% weighting was also placed on the system ability to process a set of 14 typical aerospace materials. This material set was established from analyses of previous in-flight failures that required crew 
action, along with statistical data gathered from material usage lists of several space rack and sub-rack payloads. A system score for the materials set was calculated based on the following point allotment:

$0=$ Cannot process

$1=$ Theoretically possible but not demonstrated

$2=$ Research level and/or $<90 \%$ density and strength

$3=$ Commercially available with $>=90 \%$ density and strength.

The evaluation was performed by members of the ISFR fabrication team along with the members of MSFC Rapid Prototyping Laboratory. Two processes that distinguished themselves based on current technological maturity and NASA requirements were:

- Electron Beam Melting (EBM)

- Selective Laser Sintering of Powder Bed.

Both processes offer layered fabrication advantages not achievable by typical methods, although with limited material set selections. Note that this process down select approach is not an endorsement of any particular vendor since iterative review of technological improvements is planned on a continual basis. In order to interpret the benefits and limitations of each system, it was important to determine what factors were most important to the fabrication capabilities. These factors were then used to further differentiate the two systems and allowed a down select to a single process. The following technical summary reflects the results of the down select analysis.

\section{Selective Laser Sintering (SLS)}

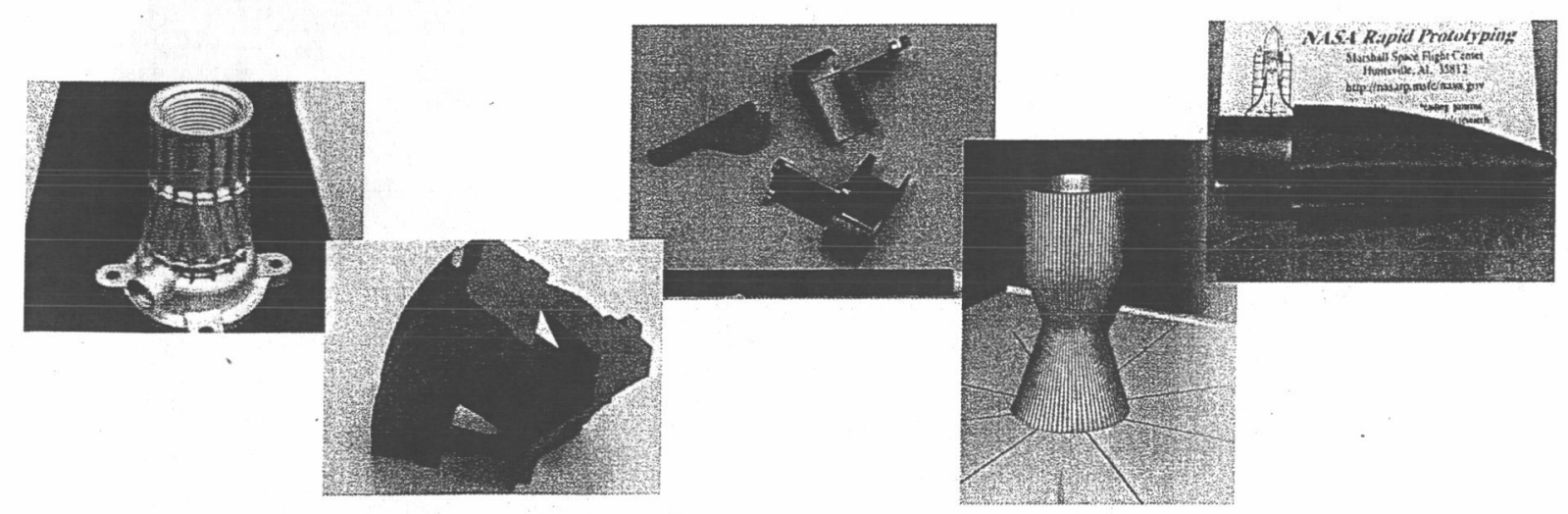

Figure 5. Demonstration Parts Produced by Selective Laser Sintering Process (Photos courtesy of Ken Cooper, MSFC RP Laboratory)

- The main characteristics that distinguish SLS from the EBM process are the surface finish and dimensional accuracy as shown in Figure 5. The SLS process clearly has the best surface finish that requires no more than minimal post-processing to arrive at a finished part. Shot peening is typically used as a post finishing method to improve surface finish.

- The set of materials processed is somewhat limited since the current selection of materials included DM-20 (bronze-based), DS-20 (steel-based mix), and DS-H20 (tool steel) materials. Additional materials are being investigated with anticipation of capability with 17-4 stainless steel in the spring of 2006, SS316 in the summer of 2006, and Inconel and titanium alloys thereafter. With the process based on a laser, the reflectivity of aluminum and copper, which are among the highest priority materials identified in this study, will pose significant challenges for this process. 
- A key feature of the SLS process is the ability to pause the system and open the door during the build. This would allow the embedding of components, such as sensors, wires, inserts, or any component requiring an enclosure that can withstand the temperature of the process, into the build.

\section{Electron Beam Melting (EBM)}

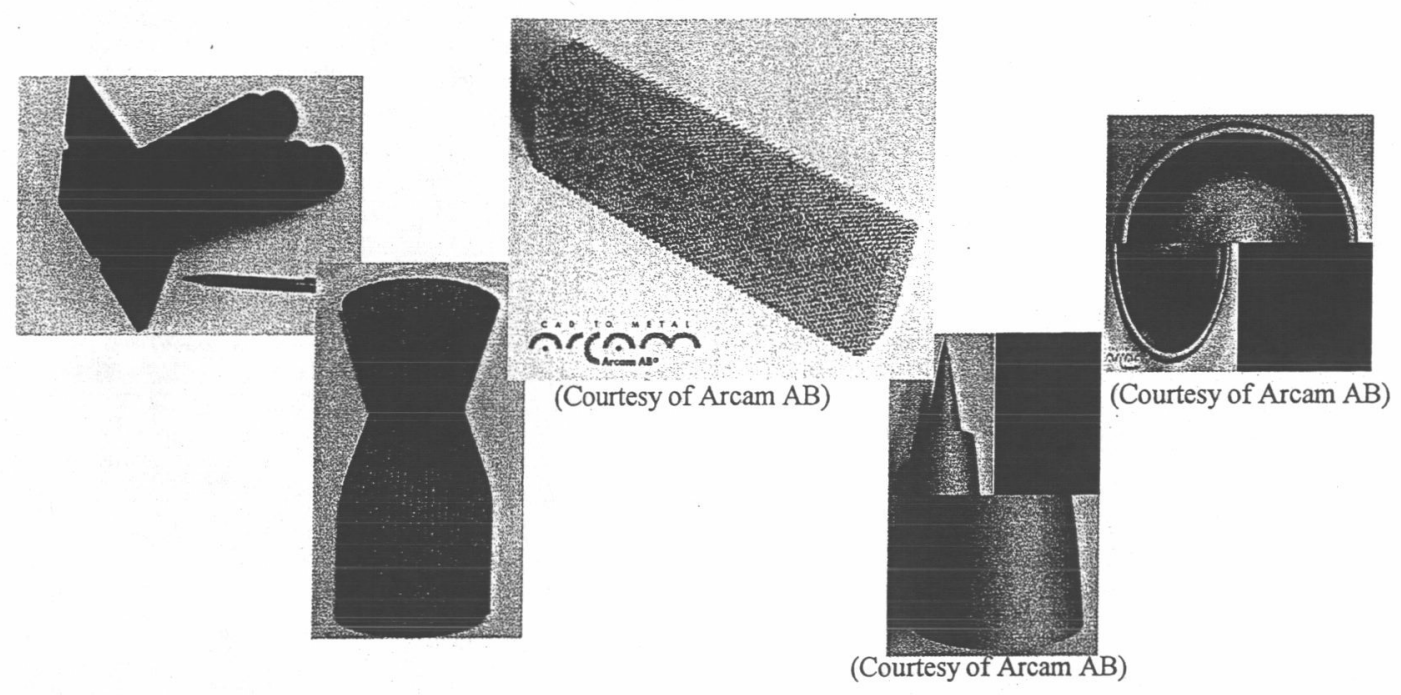

Figure 6. Demonstration Parts Produced by Electron Beam Melting Process

- The list of materials currently processed by EBM includes titanium (Ti-6Al-4V), H-13 tool steel, and cobalt-chrome. GR-COP84, a material composed of copper, chromium, and niobium, is being developed for its thermal conductivity characteristics. This material is being used to fabricate rocket engine components for Exploration missions at MSFC. Titanium and copper alloys were identified as primary materials for this study due to structural component weight savings and thermal management applications, respectively. Therefore, these materials favorably differentiated the EBM process for the applications involved with this particular study. Additional material development efforts in the coming months will include aluminum (6061), 17-4PH stainless steel, 316 stainless steel, and Inconel 718, although they are not currently available commercially for EBM.

- The EBM process is performed in a vacuum, which matches well with the lunar surface environment as well as unpressurized, in-flight environments for Exploration missions. A vacuum environment facilitates reduction of oxidation effects during high temperature processing. This positive aspect is somewhat balanced by possible adverse effects on alloys that may experience high temperature evaporation of volatile constituents.

- The EBM build volume $(250 \times 250 \times 200 \mathrm{~mm}$, per vendor specifications) is comparable to the SLS build

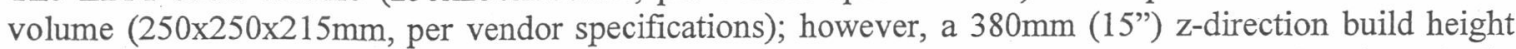
has been developed by EBM but is not commercialized at this time. A 12"-tall part has been built, weighing 10 pounds, which proves that the system is functional and should be available in the near future.

- The EBM build rate is faster than the SLS system but has a lower resolution, rougher surface finish, and lower accuracy. This observation only considers the time for a part fabricated within the machine and does not include post-processing steps that may be required to improve the surface finish. However, depending on specific user applications, parts might require little or no finish control, such as only for mating surface areas and threads.

Both of these highest ranked processes offer the flexibility of unique geometries that layered manufacturing can provide, such as internal cavities, honeycomb structures, and complex geometries that other manufacturing processes cannot provide. The final results were very close between the two systems, with future space application 
environment aspects being the deciding factors for the ISFR program. Based on the trade study factors, it was concluded by a narrow margin that the EBM process is currently best suited to the capability requirements of the ISFR program with application to future space environments.

\section{Summary}

The Fabrication Technologies sub-element has made an additive metal fabrication system selection after performing a trade study assessment of layered fabrication technologies. Targeted materials representative of typical space flight hardware requirements were identified based on historical parts failure and material usage analyses. A trade study was then performed to assess part quality and materials set capabilities existing currently and anticipated to occur in the near future. Based on the trade study factors, it was concluded that the EBM process is currently best suited to the capability requirements of the ISFR element with application to future space environments.

An EBM metal fabrication system at MSFC will be used for material set expansion development and fabrication of demonstration parts to support active programs within NASA, such as the CEV, CLV, and ECLSS, among others. Post-processing techniques will be utilized to improve the fabricated part quality, including CNC machining combined with surface shot peening and other processes. All currently scheduled and ongoing ISFR activities will be completed in FY06 as a result of NASA priority adjustments. Upon completion, all documentation and final reports will be archived in order to be available for potential future use should the ISFR capability be needed.

\section{Acknowledgments}

The authors would like to express their sincere thanks to the colleagues and industry contributors who provided information that made this research possible. Much information was gathered from system vendors and users that are experts in their fields. We would also like to thank the participants of our Technical Interchange Meeting, where the willingness to provide their knowledge will provide the direction of our current and future research.

\section{References}

1. Bioastronautics Roadmap: A Risk Reduction Strategy for Human Exploration of Space, David Longnecker and Ricardo Molins, Editors, Committee on Review of NASA's Bioastronautics Roadmap, National Research Council, October 2005.

2. Human \& Robotics Technology (H\&RT) Formulation Plan, Version 5, Development Programs Division, Office of Exploration Systems, National Aeronautics and Space Administration, 29 July 2004. 

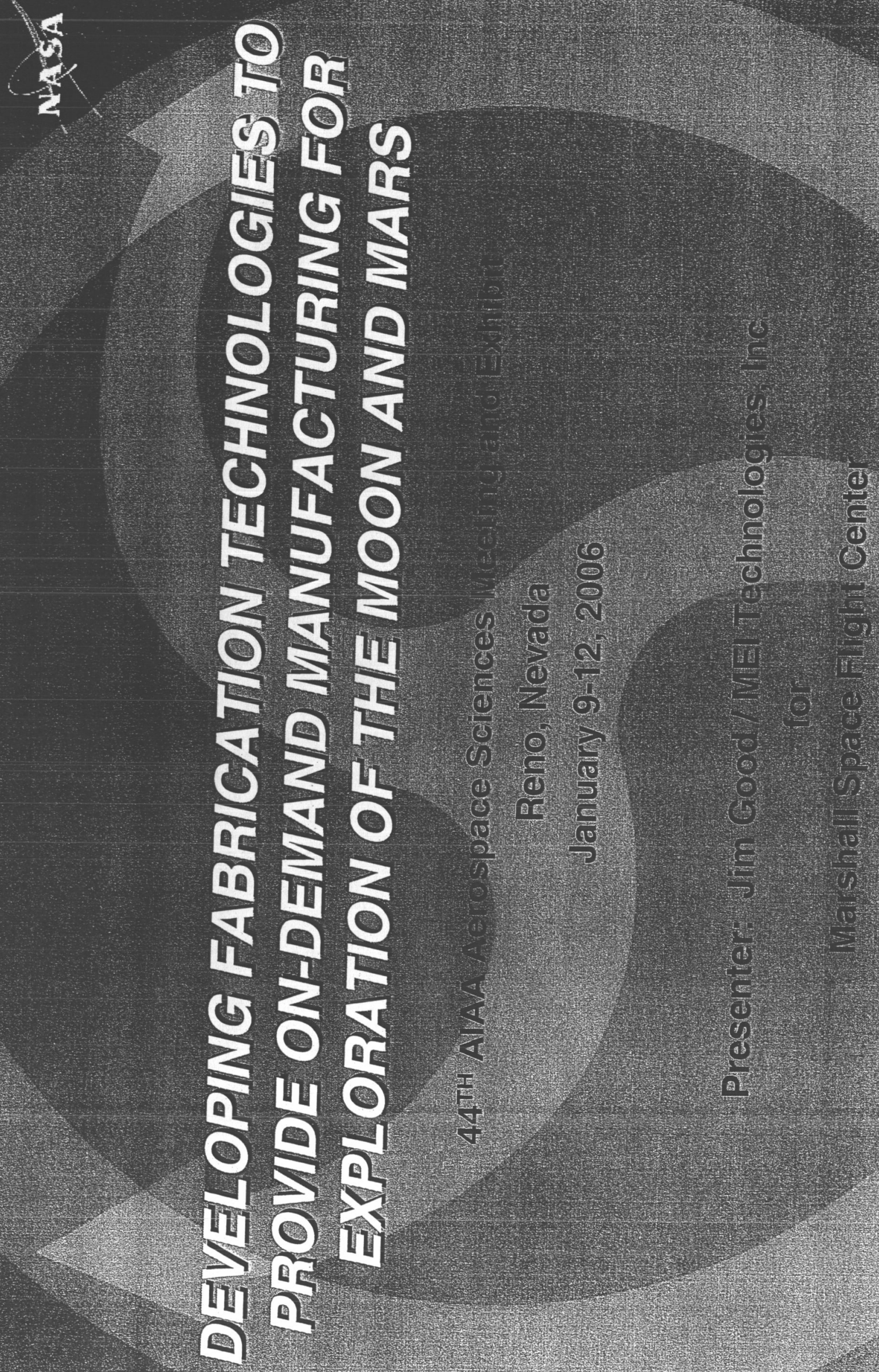


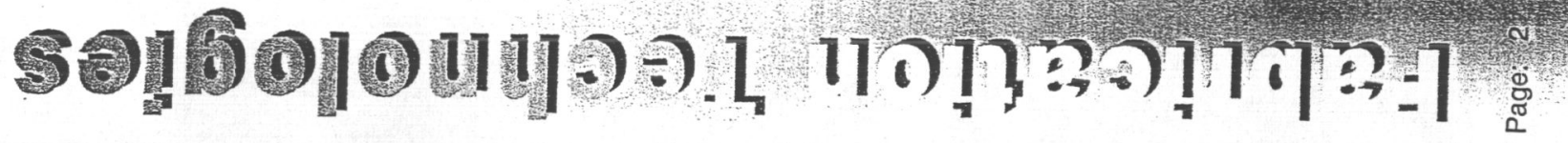

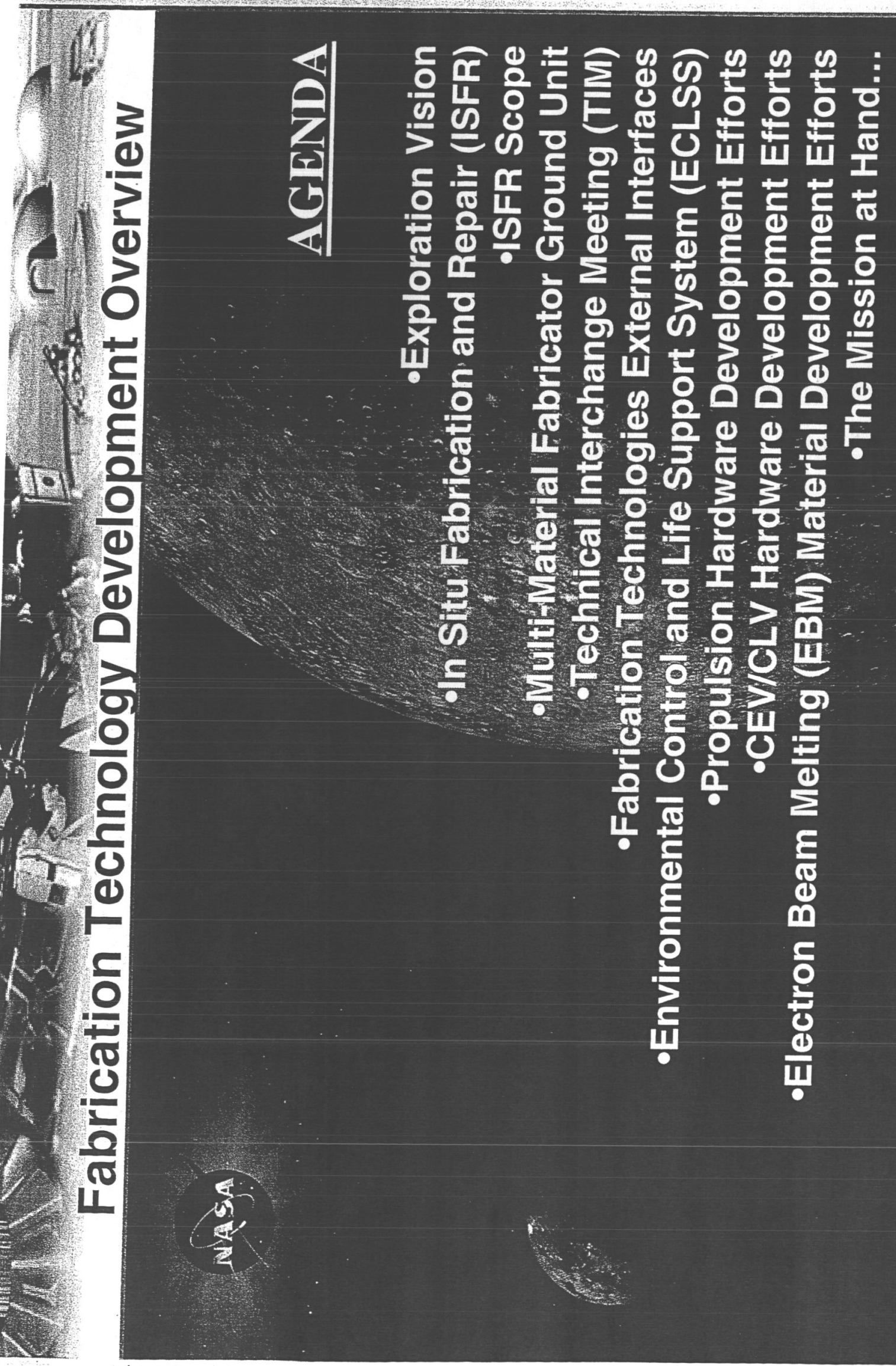




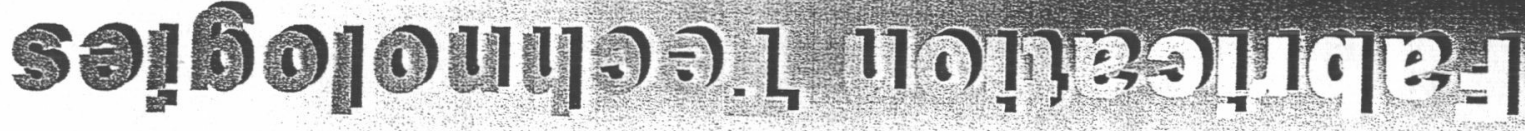

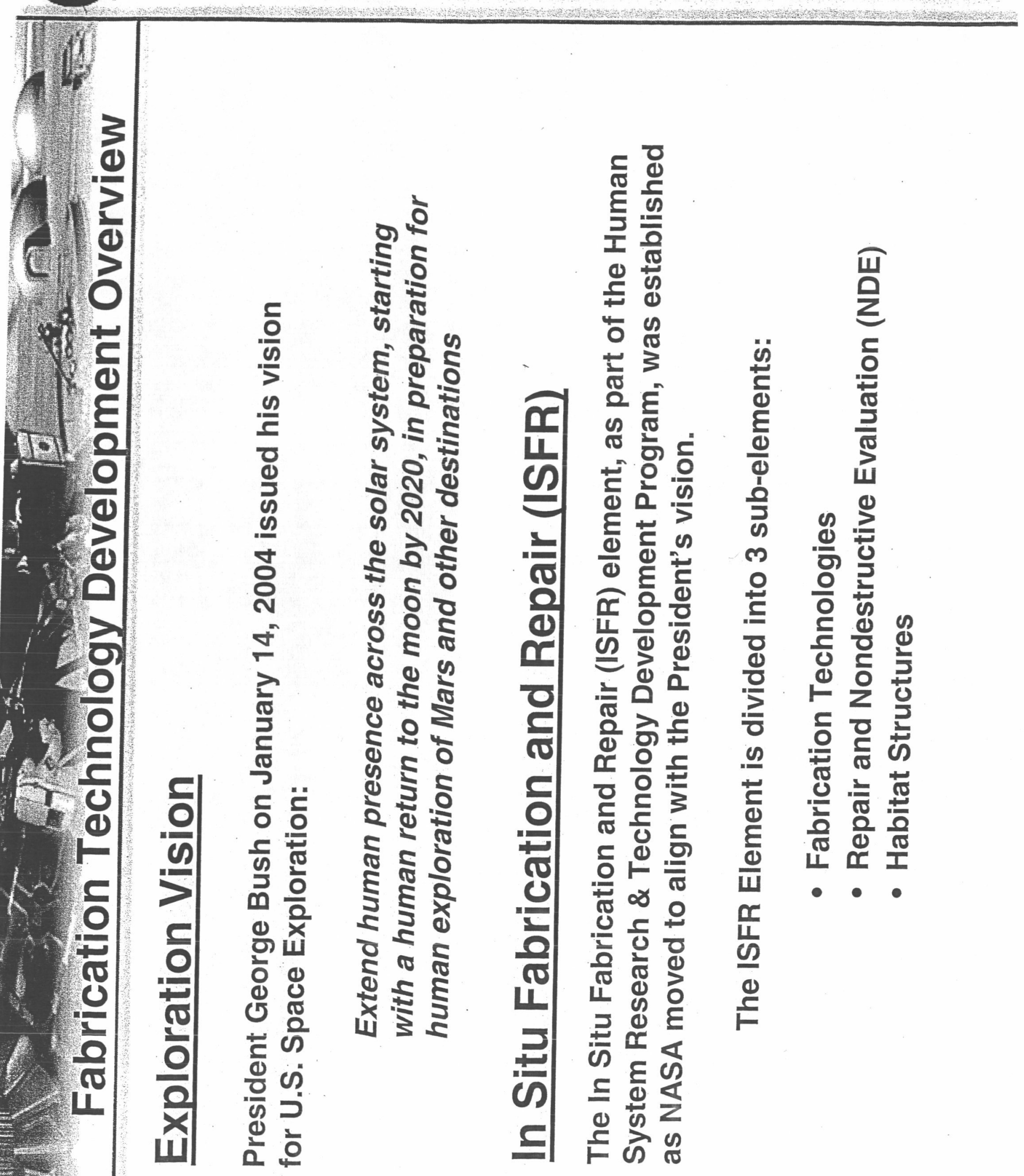




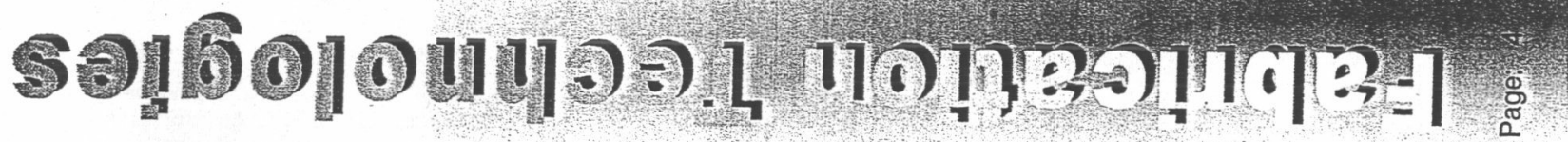

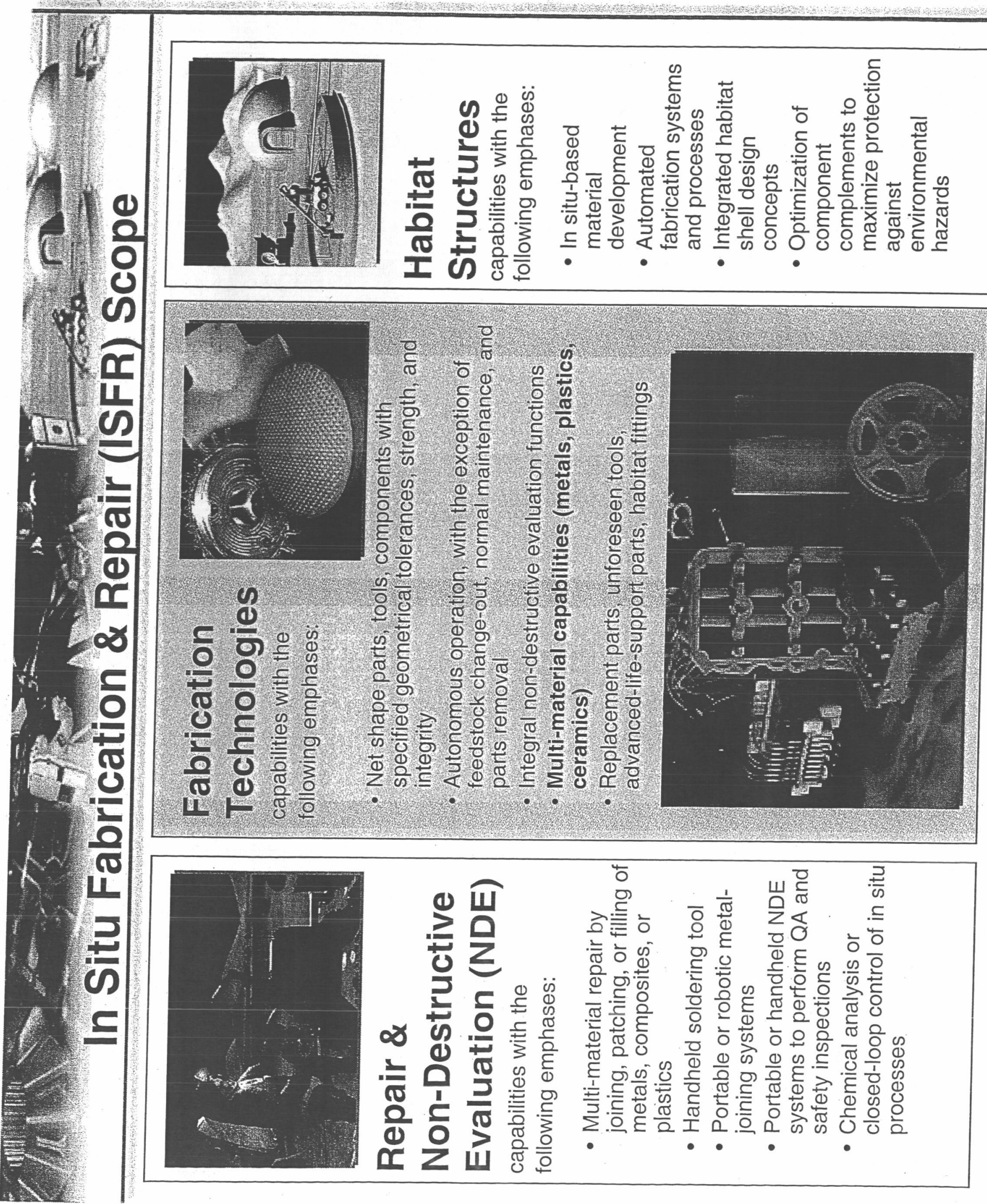




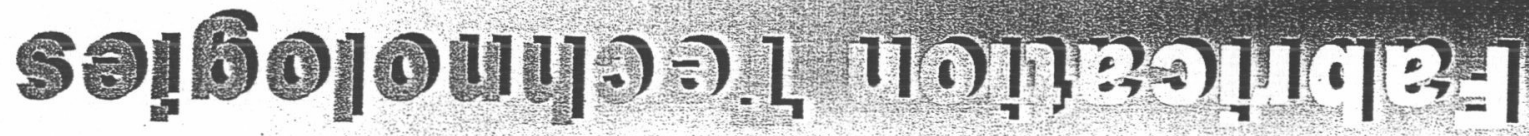

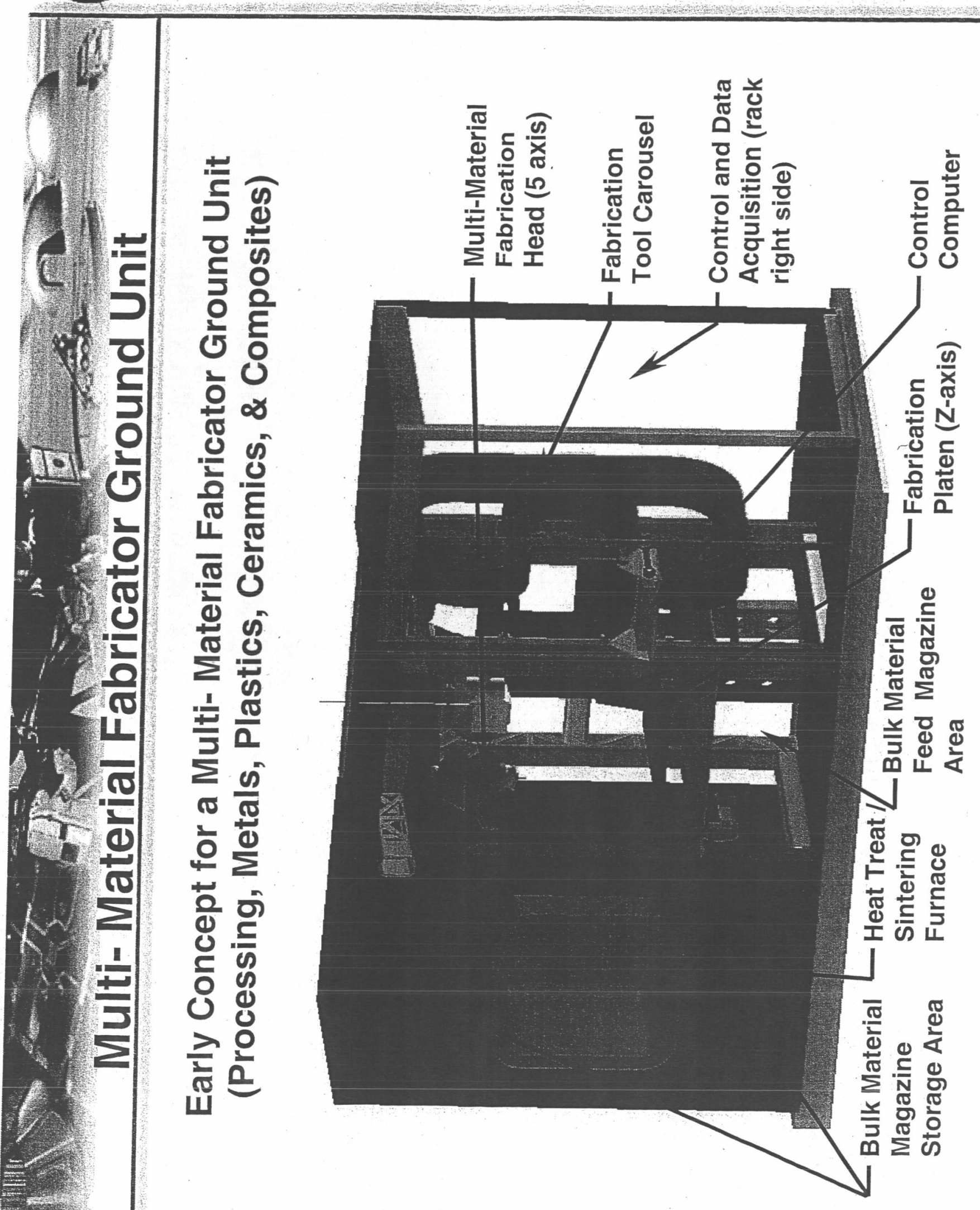




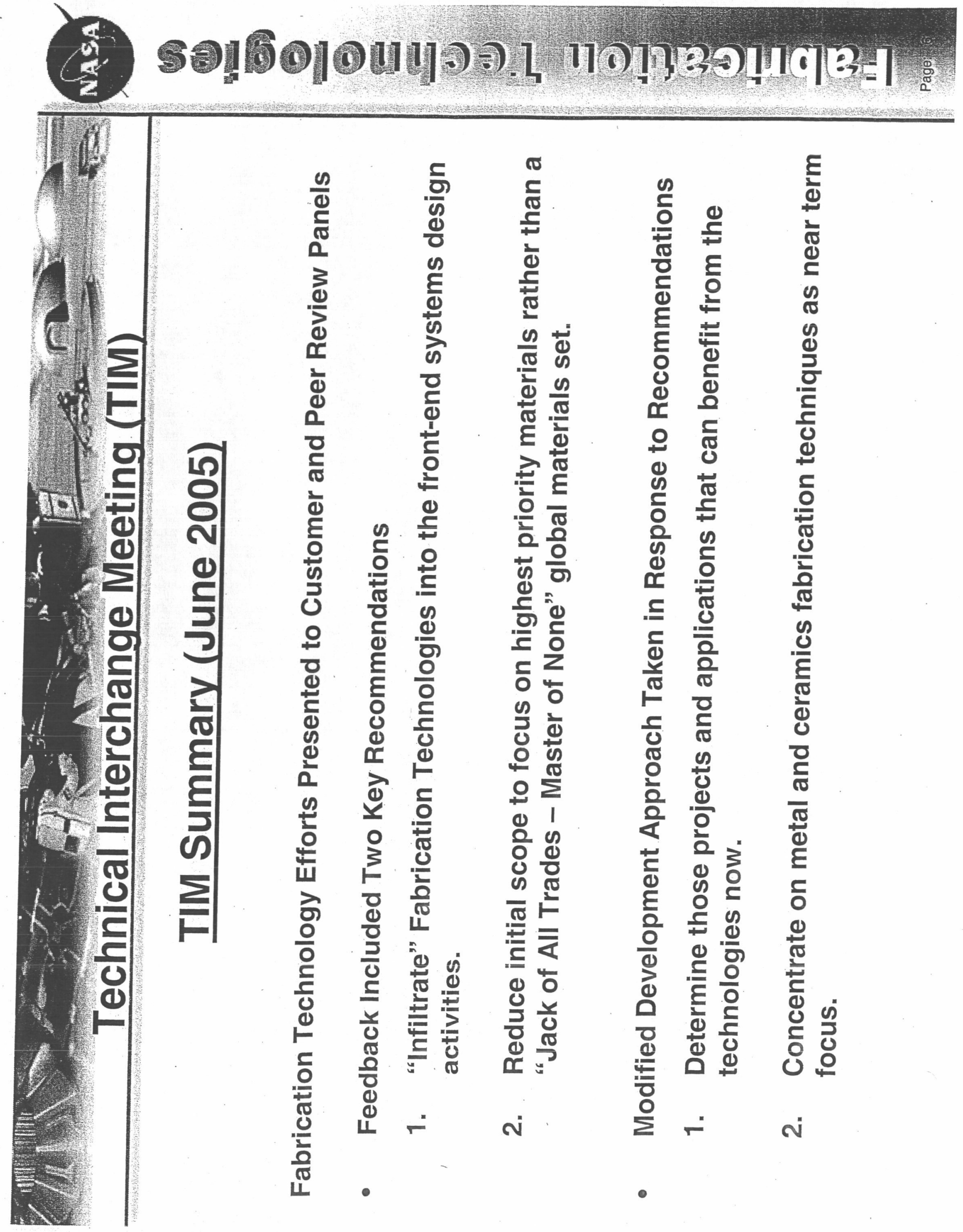




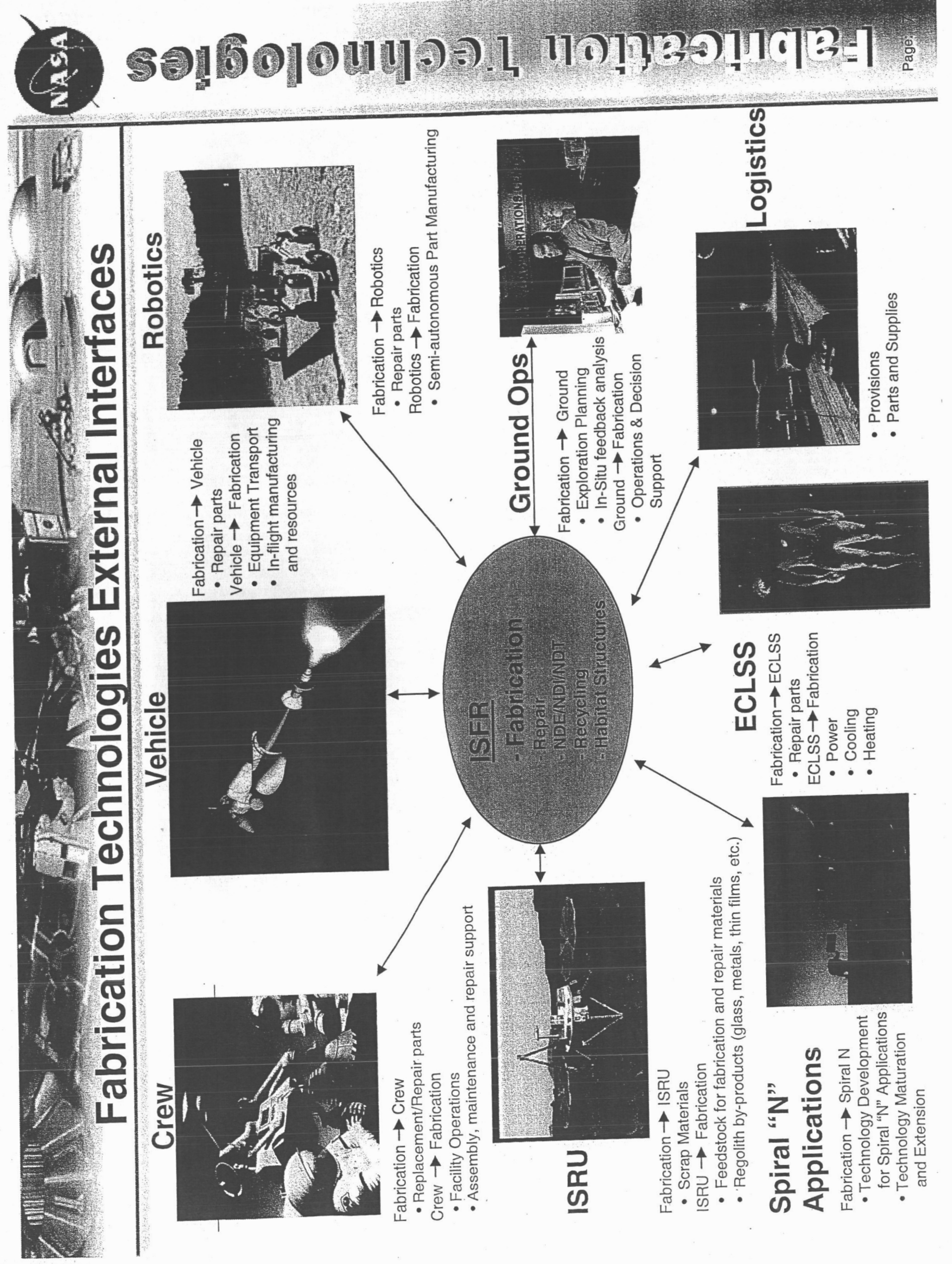




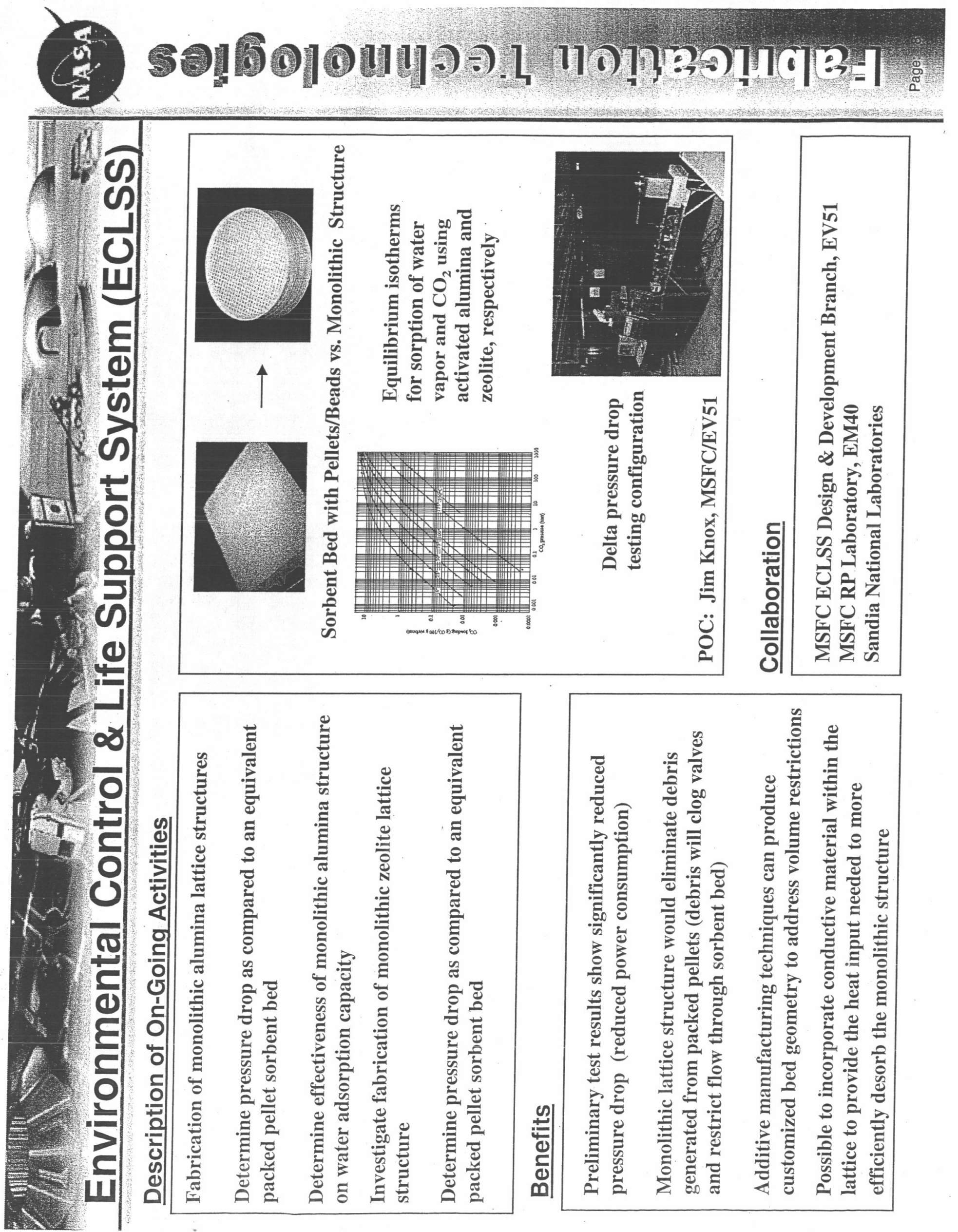




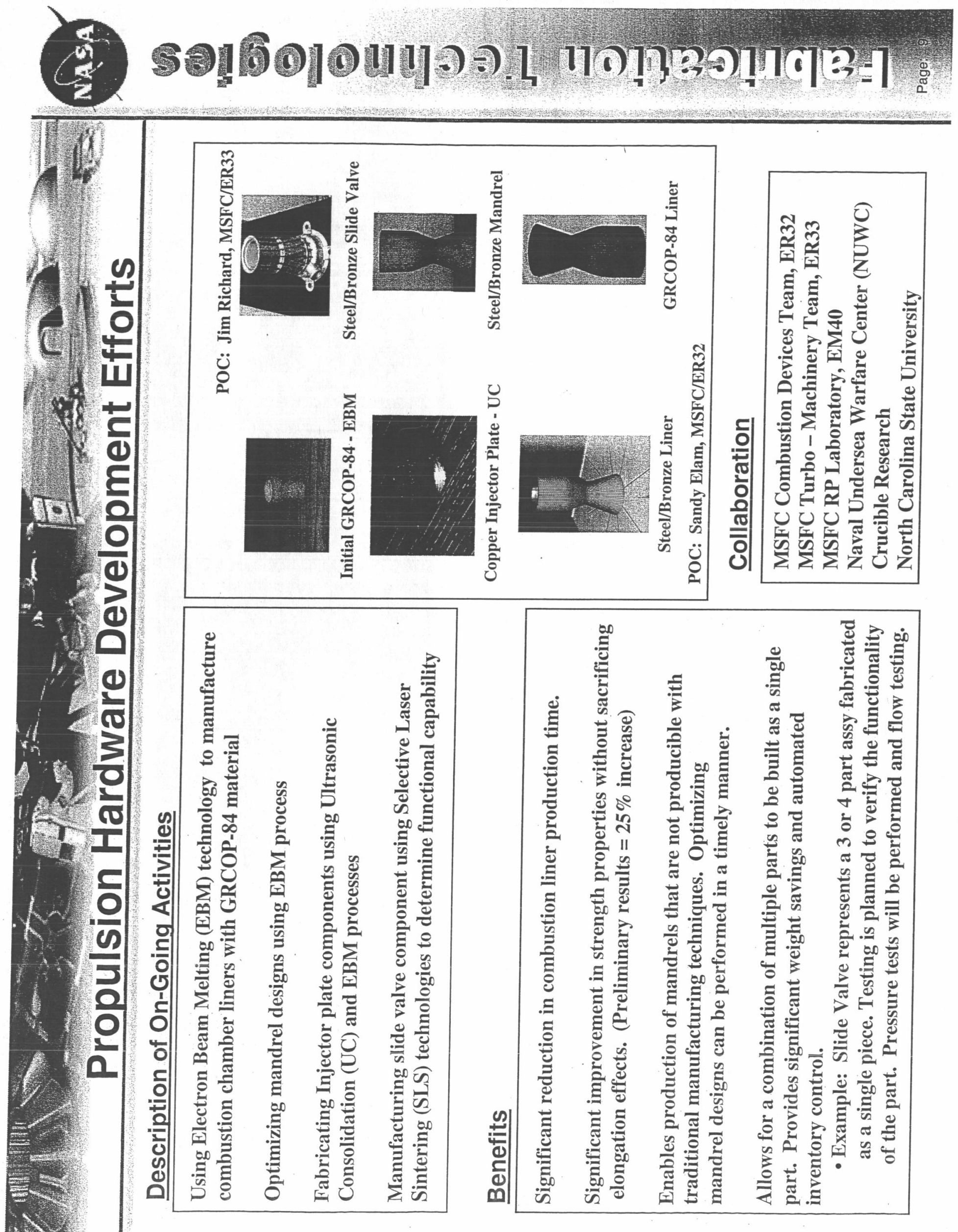




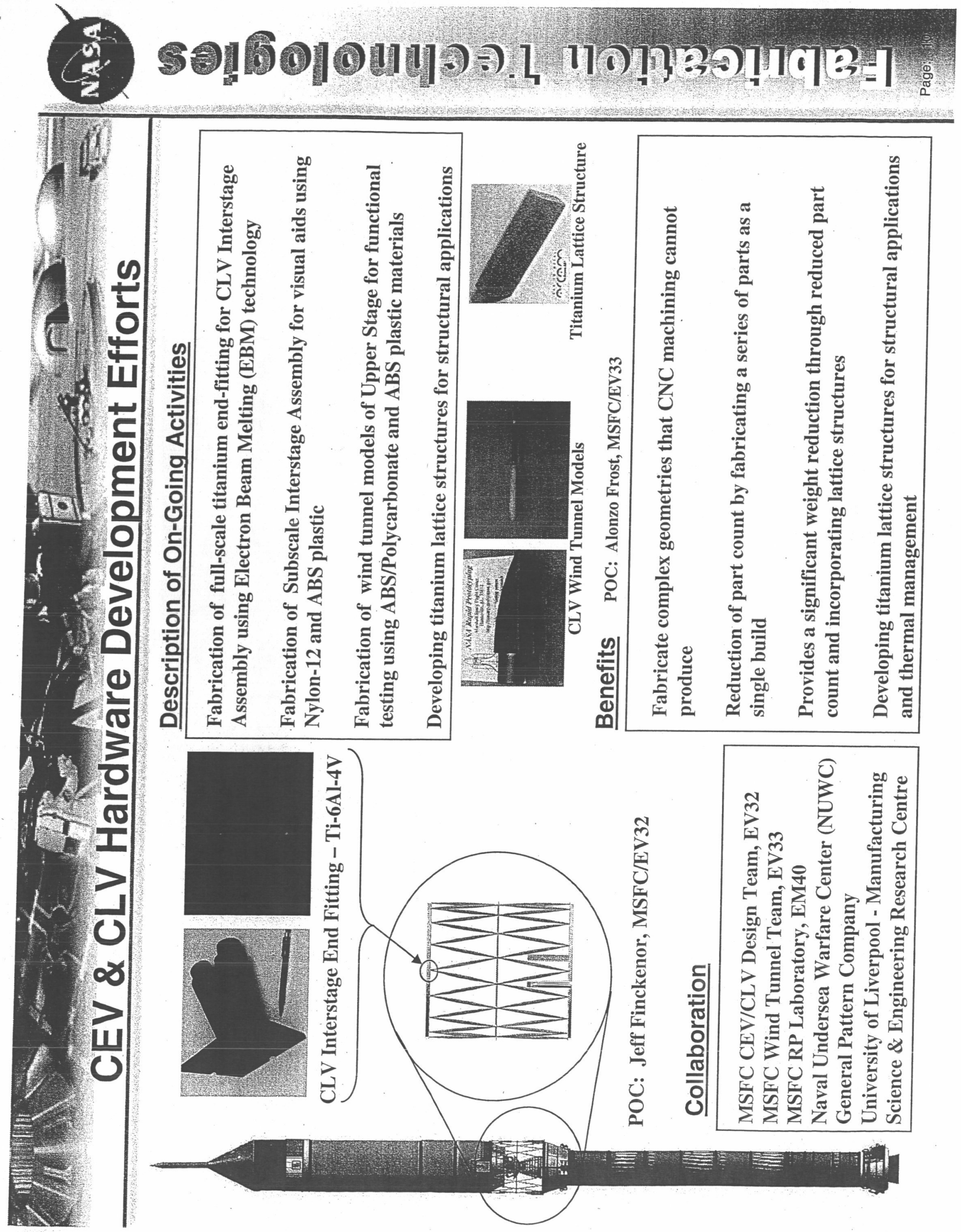




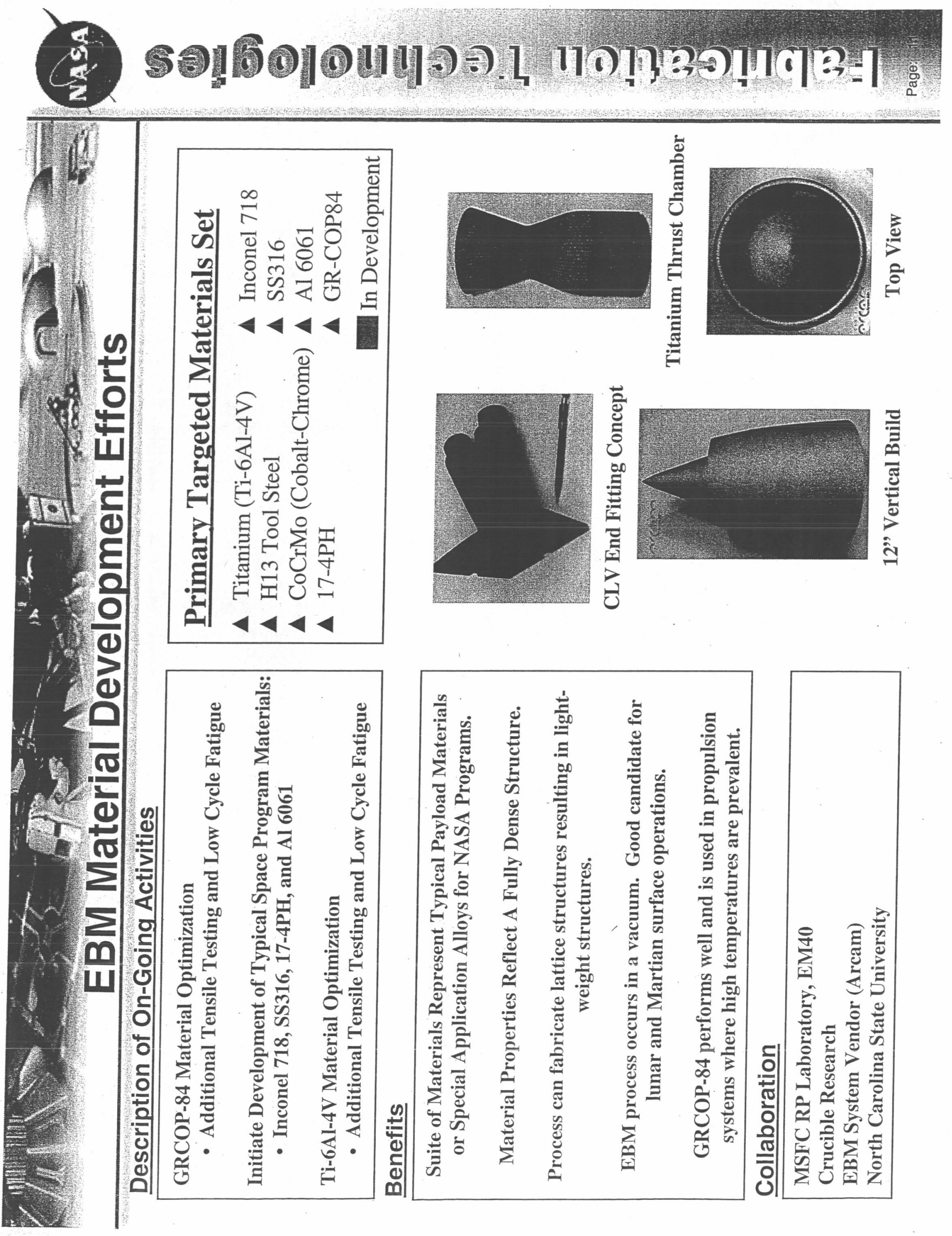




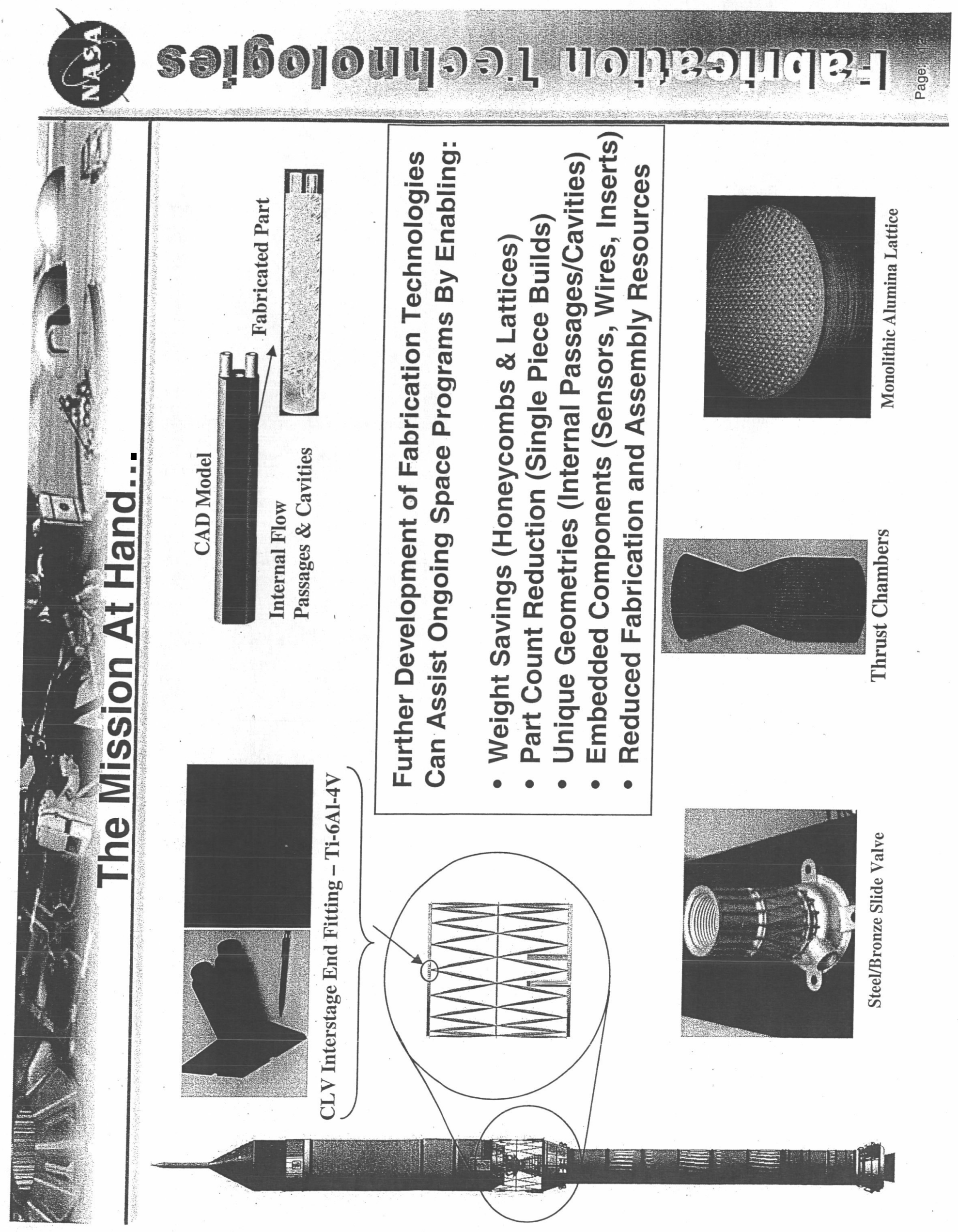

